\title{
Cyto-adherence studies of the adhesin P50 of Mycoplasma hominis
}

\author{
ANNETTE KITZEROW, ULRICH HADDING and BIRGIT HENRICH \\ Institute for Medical Microbiology and Virology and Center for Biological and Medical Research, \\ Moorenstrasse 5, Heinrich-Heine University, 40225 Düsseldorf, Germany
}

\begin{abstract}
Recombinant peptides of Mycoplasma hominis adhesin P50 were expressed in Escherichia coli to investigate which regions of the $\mathrm{P50}$ molecule are responsible for cyto-adherence. The respective DNA fragments were obtained by PCR amplification of the 550 gene with the use of mutating oligonucleotides to change the TGA codons of mycoplasma to TGG codons, which are translated in $E$. coli as tryptophan. The resulting three clones (I, I + II and I + III) contained regions of P50 which closely represent the repeat regions $\mathbf{A}, \mathbf{A}+\mathbf{B}$ and $\mathbf{A}+\mathbf{C}$. After expression in $E$. coli, the polyhistidine-tagged recombinant peptides were purified by metal chelation chromatography. The three recombinant peptides were detected in Western blot analysis by a polyclonal antiserum directed against $M$. hominis FBG and two P50-specific monoclonal antibodies, BA10 and BG2. Each of the three recombinant peptides I, I + II and I + III was able to adhere to immobilised HeLa cells in an adhesion assay. The cyto-adhesion of the peptides could be inhibited by pre-incubation with the appropriate antibody. Therefore, it is suggested that adherence may be mediated by all regions of the P50 molecule. Attachment of the recombinant peptides to immobilised HeLa cells was inhibited by high mol. wt dextran sulphate (MW 500000 ), indicating that the respective $P 50$ regions bind to sulphatides on the host cell membrane.
\end{abstract}

\section{Introduction}

Successful colonisation of the host cell by mycoplasma requires adhesion as a first step. The mycoplasmas are widely distributed [1] and the interaction between structures of the mycoplasma membrane and the corresponding host cell membrane is not uniform among the species [2]. In Mycoplasma pneumoniae and $M$. genitalium, for example, the adhesin molecules are concentrated at specific tip structures, whereas other species such as $M$. hominis lack such an attachment organelle. Studies of the cyto-adhesion of $M$. pneumoniae and $M$. genitalium show that the ability to adhere to the host cell does not seem to be mediated by only one type of molecule, but is probably a combination of the effects of several structures [3]. Different receptors for mycoplasmas have been found on host cells - such as sulphated glycolipids, sialylated glycoproteins and glycolipids [4-8].

M. hominis, a facultative human pathogen, is asso-

Received 18 June 1998; revised version received 4 Sept. 1998; accepted 6 Sept. 1998.

Corresponding author: Dr A. Kitzerow. ciated with diseases of the urogenital tract such as pelvic inflammatory disease (PID), acute pyelonephritis and postpartum fever [9]. Of the many surface antigens identified in $M$. hominis [10-13], some have been shown by monoclonal antibody (MAb) inhibition assays to play a role in cyto-adherence $[12,13]$.

The protein P50 has been shown to be a major surface protein, distributed over the whole cell membrane and to be an adhesin of the $M$. hominis isolate FBG [14]. The p50 gene was sequenced [15] and the corresponding 467-amino acid sequence showed a signal peptide of 26 amino acids and, furthermore, cysteine in position 27 which could act as an attachment site for lipoproteins [16]. Three consecutive repeats of 122,121 and 111 amino acids were found in the Cterminal part of the protein, which contain $67.1 \%$ isofunctional amino acids; $28 \%$ of the amino acids among the three repeats were identical and the repeats $A$ and $B$ have an even higher amino acid identity of $52.5 \%$. MAbs directed against P50 were able to differentiate between these repeats [15]. Zhang and Wise found size variant Vaa (variable-adherenceassociated) antigens in clonal populations of $M$. hominis strain 1620 which differed in the number of 
nearly identical repetitive elements [17]. Based on significant DNA and protein homologies they proposed Vaa-2, a 50-kDa size variant, to be the P50 homologue expressed in a different $M$. hominis strain.

This study examined the expression of recombinant peptides of P50 in Escherichia coli and the participation of regions of the P50 molecule in its adherence to HeLa cells.

\section{Materials and methods}

\section{Cell culture}

The human cervical carcinoma cell line HeLa S3 (ATCC CCL2.2) was obtained from the American Type Culture Collection (Rockville, MD, USA) and cultivated in Dulbecco's Minimal Essential Medium (Gibco/ BRL Life Technologies, Gaithersburg, MD, USA) with fetal calf serum (Gibco) $10 \%$.

\section{Bacterial strains and plasmids}

E. coli strains $\mathrm{DH} 5 \alpha \mathrm{F}^{\prime}$ and $\mathrm{DH} 5 \alpha \mathrm{F}^{\prime} \mathrm{IQ}$ (Gibco) were used for cloning and expression of recombinant peptides.

The expression vector pTRB-2His was used for subcloning the different fragments of $\mathrm{p} 50$. This plasmid is a derivative of the expression vector pTRB-2 [15] in which the fusion partner $\beta$-galactosidase has been replaced by six histidines, which enables purification of the recombinant peptides through binding to $\mathrm{Ni}$ NTA-agarose.

\section{DNA manipulation}

All routine DNA manipulation techniques including plasmid preparation, restriction endonuclease analysis, ligation and transformation of $E$. coli were performed as described by Sambrook et al. [18] or according to the manufacturer's instructions.

\section{$P C R$, cloning and sequencing of the DNA fragments}

To generate the different clones intended for expression, oligonucleotides were used as primers in PCR assays to change the codon TGA to TGG. In addition, to enable cloning of the PCR products, restriction sites were included in the primers without changing the resulting amino acid sequence.

The PCR was performed under the following conditions with a DNA thermal cycler (Biometra, Göttingen, Germany) in a volume of $100 \mu \mathrm{l}$ : template $100 \mathrm{ng}, 300 \mathrm{nM}$ each primer, $200 \mu \mathrm{M}$ each dNTP, $1 \times$ High Fidelity Expand buffer with $1.5 \mathrm{mM} \mathrm{MgCl}_{2}$ and 2.5 U Expand High Fidelity Polymerase (Boehringer Mannheim, Germany) were heated for $3 \mathrm{~min}$ at $96^{\circ} \mathrm{C}$ and then for 35 cycles of $1 \mathrm{~min}$ at $96^{\circ} \mathrm{C}, 1.5 \mathrm{~min}$ at $53^{\circ} \mathrm{C}, 1 \mathrm{~min}$ plus $3 \mathrm{~s}$ each cycle at $65^{\circ} \mathrm{C}$ ). The genomic clones Hind $2 \mathrm{~kb}$ and Hind $7 \mathrm{~kb}$ [15] containing the p50 gene were used as templates. The PCR products were purified with a QIAGEN PCR purification kit (QIAGEN, Hilden, Germany). After digestion with the appropriate restriction endonucleases (Nsi I, HindIII, XbaI) the fragments were excised from agarose gels and purified with a QIAEX gel extraction kit (QIAGEN). The fragments were ligated in the reading frame of the pTRB2His vector and were propagated into the $E$. coli strains $\mathrm{DH} 5 \alpha \mathrm{F}^{\prime}$ and DH5 $\alpha \mathrm{F}^{\prime} \mathrm{IQ}$. After induction on IPTG-plates, the recombinants were screened with the antibodies as described previously [15].

The cloned fragments were sequenced on an ABI 373A with the Taq Cycle Sequencing Kit (Perkin Elmer Applied Biosystems, Weiterstadt, Germany).

\section{Oligonucleotides}

The oligonucleotides used as primers in PCR amplification were synthesised with a solid carrier on an Applied Biosystems 381A machine by the phosphoamidite method [19] by Dr Heiner Schaal (Institute for Medical Microbiology and Virology, Heinrich-HeineUniversity, Düsseldorf, Germany). Table 1 shows their detailed position in relation to the p50 gene sequence (EMBL data library, accession no. $X$ 73834).

\section{Antibodies}

The preparation and purification of MAbs BA10 and BG2 (both IgG) and a polyclonal anti-M. hominis FBG rabbit serum ( $\mathrm{r}-\mathrm{PAb}$ ) have been described previously [14]. The polyclonal serum and the hybridoma supernates each had an antibody titre of 1 in 10000 . The epitopes of the MAbs were mapped on repeat B (BA10) and repeat C (BG2) of P50 [15]. The r-PAb was used to detect peptide I.

\section{Expression and purification of recombinant peptides}

For expression and purification of the different peptides, $400 \mathrm{ml}$ of 2YT-medium (bacto-tryptone $16 \mathrm{~g}$, bacto-yeast extract $10 \mathrm{~g}, \mathrm{NaCl} 5 \mathrm{~g} / \mathrm{L}$ ) containing ampicillin $50 \mathrm{mg} / \mathrm{L}$ and kanamycin $10 \mathrm{mg} / \mathrm{L}$ were inoculated with $4 \mathrm{ml}$ of an overnight culture of the appropriate bacterial strain and incubated for 3-4 h at $37^{\circ} \mathrm{C}$ with vigorous shaking until an $A_{600}$ of $0.6-0.9$ was reached. Protein expression was induced by incubation for a further $3 \mathrm{~h}$ at $37^{\circ} \mathrm{C}$ after addition of $1 \mathrm{mM}$ IPTG (isopropylthio- $\beta$-D-galactoside). The cells were harvested by centrifugation $\left(1500 \mathrm{~g}, 20 \mathrm{~min}, 4^{\circ} \mathrm{C}\right)$ and frozen at $-70^{\circ} \mathrm{C}$. After thawing on ice the cells were resuspended in $20 \mathrm{ml}$ of $50 \mathrm{mM}$ sodium phosphate (pH 7.8), $300 \mathrm{mM} \mathrm{NaCl}$ followed by the addition of lysozyme $(1 \mathrm{mg} / \mathrm{ml})$ and incubation for $45 \mathrm{~min}$ at $4^{\circ} \mathrm{C}$; 
DNAase I $(25 \mu \mathrm{g} / \mathrm{ml})$ and RNAase A $(10 \mu \mathrm{g} / \mathrm{ml})$ were added and incubated for a further $45 \mathrm{~min}$ at $4^{\circ} \mathrm{C}$. The lysate was centrifuged $\left(15000 \mathrm{~g}, 20 \mathrm{~min}, 4^{\circ} \mathrm{C}\right)$ and the supernate was removed. The pellet was resuspended in $\mathrm{H}_{2} \mathrm{O}$, which served as a washing step for inclusion bodies, which are accumulations of newly synthesised peptides as non-native aggregates [20]. In the case of viscous solutions, DNAase I $(25 \mu \mathrm{g} / \mathrm{ml})$ was added and incubated for $15 \mathrm{~min}$ at $4^{\circ} \mathrm{C}$. After centrifugation $\left(15000 \mathrm{~g}, 20 \mathrm{~min}, 4^{\circ} \mathrm{C}\right)$ the inclusion bodies were solubilised overnight at room temperature in $6 \mathrm{M}$ guanidine- $\mathrm{HCl}, 0.1 \mathrm{M}$ sodium phosphate, $0.01 \mathrm{M}$ Tris$\mathrm{HCl}$ ( $\mathrm{pH} \mathrm{8.0)}$. All the following steps were performed at room temperature. After centrifugation for $30 \mathrm{~min}$ at $15000 \mathrm{~g}$, the supernate was incubated with $600 \mu \mathrm{l}$ of a $50 \%$ slurry of Ni-NTA resin (QIAGEN) in a batch procedure for $1.5 \mathrm{~h}$. A column was packed and washed consecutively with buffers $\mathrm{B}(8 \mathrm{M}$ urea, $0.1 \mathrm{M}$ sodium phosphate, $0.01 \mathrm{M}$ Tris- $\mathrm{HCl}, \mathrm{pH} 8.0$ ) and $\mathrm{C}$ (buffer $\mathrm{B}$, pH 6.8). Each step was considered completed when an $\mathrm{OD}_{280}<0.01$ was reached. A final wash with $3 \times 1 \mathrm{ml}$ buffer $\mathrm{C}$ plus $10 \mathrm{mM}$ imidazole was performed before elution with $0.3-0.5-\mathrm{ml}$ fractions of buffer $C$ plus $150 \mathrm{mM}$ imidazole. Samples of the last washing step and the eluate fractions were examined by SDS-PAGE [21] and stained with Coomassie Brilliant Blue R-250. The fractions containing the purified peptides were pooled and dialysed once against $4 \mathrm{M}$ urea/PBS and twice against $2 \mathrm{M}$ urea/PBS (each for $8-14 \mathrm{~h}$ at $4^{\circ} \mathrm{C}$ ). Thereafter the insoluble peptides were sedimented $(15000 \mathrm{~g}, 20 \mathrm{~min})$ and the supernate containing soluble peptide was stored at $-20^{\circ} \mathrm{C}$. The protein concentration was determined by the method of Bradford [22]. The Ni-NTA chromatography resulted in recovery of the recombinant peptide at a purity of $60-70 \%$.

\section{SDS-PAGE and immunostaining of recombinant peptides}

For immunostaining, the proteins were separated on a polyacrylamide $12 \%$ slab gel with SDS $0.1 \%$ and transferred to nitrocellulose (Schleicher and Schüll, Dassel, Germany) with a semi-dry blot apparatus (Phase, Mölln, Germany). The immunobinding procedure was performed by the method of Kotani and McGarrity [23] with modifications as described previously [24]. As a peroxidase substrate, 4-chloro-1naphthol (Sigma, Deisenhofen, Germany) or ECLLuminol (Amersham Buchler, Braunschweig, Germany) was used following the suppliers' protocol.

\section{Preparation and purification of P50}

The P50 protein was isolated from $M$. hominis isolate FBG as described by Feldmann et al. [14].

\section{Adhesion and inhibition assays}

The adhesion and inhibition assays with native P50 and the recombinant peptides were performed by a cell
ELISA method as described by Henrich et al. [12] with the following modifications. HeLa cells $\left(1 \times 10^{5}\right.$ cells/well) were fixed with glutaraldehyde on 96-well Micro-Plates (Greiner, Frickenhausen, Germany) as described by Ofek et al. [25] and pre-incubated in DMEM containing fetal calf serum $10 \%(200 \mu \mathrm{l} /$ well $)$ for $45 \mathrm{~min}$ at $37^{\circ} \mathrm{C}$. The proteins were diluted in DMEM with fetal calf serum $10 \%$. Cyto-adherent P50 and recombinant peptides were detected with polyclonal anti- $M$. hominis FBG rabbit serum (initial dilution 1 in 10), MAb BA10 (initial dilution 1 in 10) and MAb BG2 by peroxidase-coupled goat antirabbit IgG (1 in 4000; Boehringer Mannheim) or goat anti-mouse $\operatorname{IgG}$ (1 in 5000; Dianova, Hamburg, Germany).

\section{Binding of P5O and the recombinant peptides to HeLa cells in the presence of dextran sulphate}

The adherence of P50 and its recombinant peptides to immobilised HeLa cells was examined in the presence of dextran sulphate (DS; Sigma) with mol.wts of 500000 (high-mol. wt DS) and 5000 (low-mol. wt DS). Binding of native P50 and the recombinant peptides to HeLa cells in the presence of DS was detected with polyclonal anti- $M$. hominis FBG serum ( 1 in 50 ). The assay was performed as described in the adhesion assay with concentrations of DS from 5 to $1000 \mu \mathrm{g} / \mathrm{ml}$.

\section{Results \\ Construction of the clones}

Recombinant peptides expressed in $E$. coli were used to investigate the regions of the P50 adhesin molecule that are involved in the attachment of this mycoplasma protein to the host cell. The codon TGA, a stop codon in the universal code, translates for tryptophan in most mycoplasma species $[26,27]$. The p50 gene possesses seven TGA codons, and oligonucleotides were used in the PCR to change six of them for the protein expression in $E$. coli. Restriction sites were added to these primers for the cloning of fragments in an expression vector without changing the resulting amino acid sequence (Table 1). The positions of the TGA codons and the additional restriction sites are indicated in Fig. 1. Amplification of the regions Nsi I-HindIII, HindIII-(HindIII) and (HindIII)- (XbaI) yielded three fragments, I, II and III respectively, encoding approximately the three repeats found in P50 [15]. Fragment I, which included most of the N-terminal region of the mature protein and $89 \%$ of the repeat $\mathrm{A}$, was ligated in the expression vector pTRB2His which expresses six $\mathrm{N}$-terminal codons for the amino acid histidine. This His-tag allowed rapid protein purification by metalchelation chromatography with the Ni(II)-NTA-resin. Fragment II (HindIII-HindIII) and fragment III (HindIII-XbaI), which comprised large areas of the repeats $B$ and $C$ (Fig $1 \mathrm{~b}$ ), were subcloned in plasmids already carrying fragment I by using the HindIII 
Table 1. PCR primer pairs

\begin{tabular}{lcl}
\hline Fragment & $\begin{array}{c}\text { Nucleotide } \\
\text { position }\end{array}$ & Oligonucleotide sequence \\
\hline I & $504-530$ & 5'CAA ATG CAT TAG CAG AAG \\
& AAT TGA AAA 3' \\
& $978-1031$ & 5'ATC AAG CTT TTT TAA CTT \\
& CTT CCC ATT CTG ATA CGA TTT \\
& TTT CAA GCC ATG AGG 3' \\
II & 5'AAA AGC TTG GTC AAA AGA \\
& ATT AGC 3' \\
III & $1368-1394$ & 5'TTC AAG CTT CTT GTA CTT \\
& TTG CCC ATT 3' \\
& $1383-1409$ & 5'AAG AAG CTT GGA AAA ATG \\
& AAT TAG CAG 3' \\
& 5' TTT TCT AGA ACC ATG TGG \\
& & TAT TC 3' \\
\hline
\end{tabular}

restriction site of fragment $I$, thus generating the clones I + II and I + III. The recombinant clones I + II and I + III were screened by colony hybridisation with the MAbs BA10 and BG2 which recognise epitopes on repeats $B$ and $C$ of P50. Several positive clones were tested for their expression capacity in Western blotting with the $E$. coli lysates after induction of protein expression with IPTG. Each generated clone was also analysed to verify the sequence and resulting open reading frame.

\section{Expression of the cloned fragments}

The different clones revealed marked heterogeneity in expression and preparation. While expression and purification of fragment I was simple, fragments II and III alone displayed lower level expression in $E$. coli and were subjected to proteolysis (data not shown).
Fused with fragment I, both fragments were expressed in full length in $E$. coli and the recombinant peptides could be purified on a Ni-NTA resin. Fragment I + III showed 10-20-fold higher expression than fragment I + II. The recombinant peptides were expressed as insoluble proteins (inclusion bodies) in $E$. coli and were purified under denaturing conditions in a $6 \mathrm{M}$ guanidine-buffer. Lower IPTG concentrations and lower culture temperature had no effect on the formation of the inclusion bodies. After binding of the His-tagged proteins under denaturing conditions to the Ni-NTAagarose, the proteins were eluted through competition with imidazole, which displaces the recombinant protein from the Ni-NTA [28].

After elution of the recombinant proteins from the $\mathrm{Ni}$ NTA resin with $150 \mathrm{mM}$ imidazole in $8 \mathrm{M}$ urea buffer, the appropriate fractions were pooled and dialysed against decreasing concentrations of urea to $2 \mathrm{M}$ to permit protein refolding. When the peptides were dialysed against buffer without urea, they became insoluble and formed aggregates.

The purified proteins of the constructs I + II and I + III showed an additional band with a mol.wt. of 30100 in Coomassie staining, corresponding well with the mol. wt of peptide I (see below). Whether this was caused by proteolysis or ineffective translation of the complete protein was not investigated. The amount of this contaminating band was higher in the expression of fragment I + II than that of fragment I + III, so that a second purification step, affinity chromatography with MAb FE6-coupled Sepharose 4B [12], was necessary. MAb FE6 binds specifically to an epitope in the P50 fragment II [15]

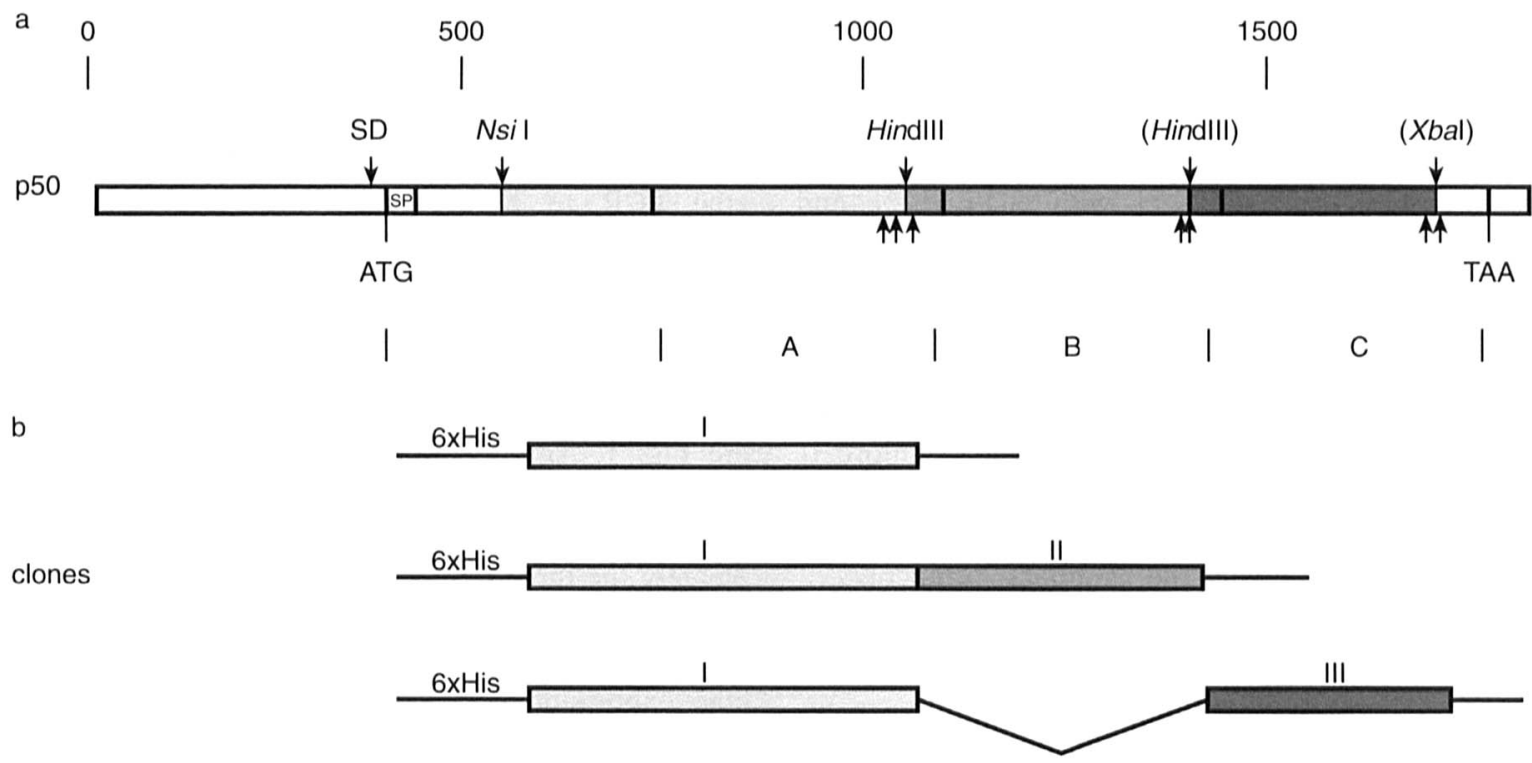

Fig. 1. Physical map of the p50 gene and structure of the different p50 constructs which were cloned and expressed in E. coli. (a) The arrows mark point mutations changing TGA to TGG for tryptophan expression. The restriction sites which were formed through the oligonucleotides used in the PCR are marked with brackets. SD, Shine-Dalgarno sequence; SP, signal peptide. The three repetitive elements A, B and C of P50 are indicated below the p50 gene. (b) Clones I, I + II and I + III used for expression in E. coli in comparison with the appropriate regions on the p50 gene (shaded areas). 
The different peptides were then analysed by SDSPAGE (Fig. 2A) and tested in Western blotting with MAbs BA10 and BG2 directed against the repeats B and $\mathrm{C}$ [15] and r-PAb (Fig. 2B), which detects peptide I. The mol.wts of the recombinant peptides were estimated to be 30100 for peptide I (lane 3); 44200 for peptide I + II (lane 4) and 39300 for peptide I + III (lane 5) by SDS-PAGE. The theoretical mol. wts were 23400 for peptide I, 37400 for peptide I + II and 35100 for peptide I + III. This discrepancy between the theoretical and apparent mol.wts may be attributed to the His-tag of the recombinant peptides. Proteins with a His-tag often appear several $\mathrm{kDa}$ larger than expected on SDS-PAGE (QIAGEN instruction manual).

Fig. 2 shows that all three recombinant proteins were detected by the polyclonal anti- $M$. hominis FBG serum (Fig. 2B); MAbs BA10 (Fig. 2C) and BG2 (Fig. 2D) recognised only the appropriate fragment I + II and I + III, as expected.

\section{Adhesion and inhibition}

The adhesion of the recombinant peptides to glutaraldehyde-fixed HeLa cells was examined to identify which regions of the P50 protein take part in the process of mycoplasmal attachment to a host cell. In a specific
cell-ELISA, established as described previously [12], each of the three peptides (I, I + II and I + III) showed attachment to HeLa cells. As shown in Fig. 3, the cytoadhesion characteristics of P50 detected with different antibodies were similar, whereas the adhesion curves of the peptides differed from each other. The peptide representing fragment I showed a lower adhesion capacity than peptide I + II and I + III, considering the difference in the molarities of the peptides which resulted from equal protein concentrations used in the assays. Pre-incubation of the recombinant peptides with the respective antibody inhibited the adherence of the expressed peptides in all cases. Because denaturing conditions were used to achieve solubility of the recombinant peptides, the adhesion assays of P50 and the recombinant peptides had to be carried out in the presence of at least $0.2 \mathrm{M}$ urea. Control experiments did not show a significant change in antibody affinity with increasing amounts of urea up to $2 \mathrm{M}$. As a control, preincubation of the recombinant peptide I + III with MAb BA10 (which recognised an epitope in peptide II) showed no effect on the adherence of peptide I + III on HeLa cells (data not shown).

In contrast to the MAbs, a weak non-specific binding of the polyclonal anti-M. hominis FBG serum to HeLa cells was observed and was taken into consideration in the analysis of the data.
A

M $12 \begin{array}{llll}2 & 3 & 4 & 5\end{array}$

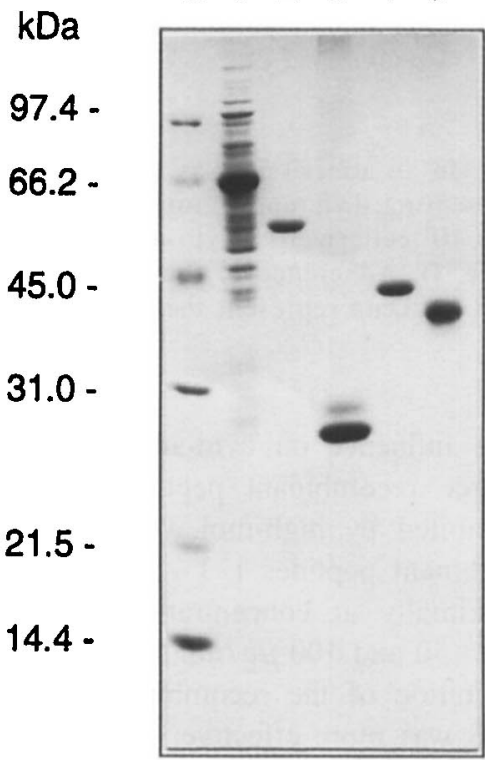

Coomassie
B
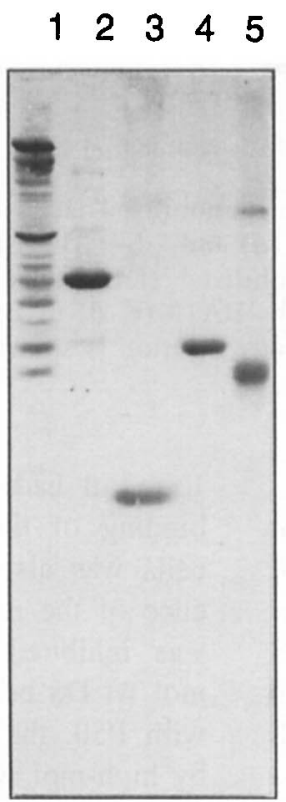

$r-P A b$
C

$\begin{array}{lllll}1 & 2 & 3 & 4 & 5\end{array}$

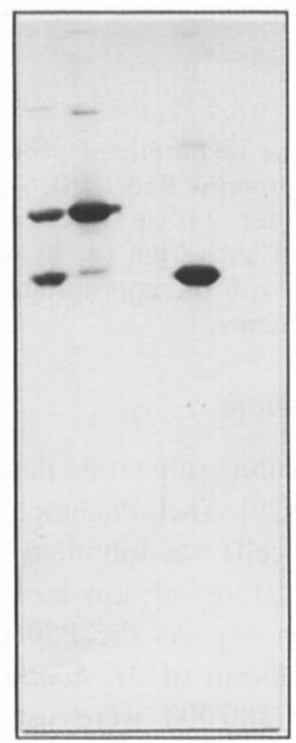

BA10 $\begin{array}{lllll}1 & 2 & 3 & 4 & 5\end{array}$

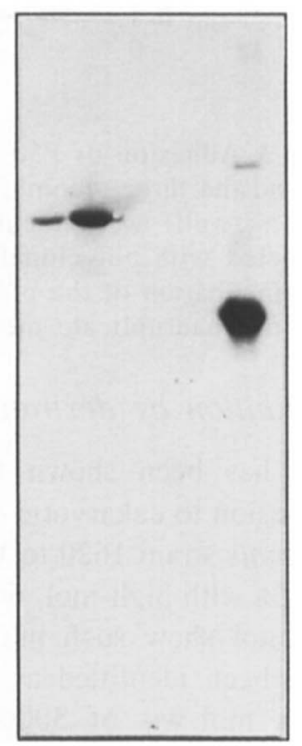

BG2

Fig. 2. Expression and immunostaining of the recombinant P50 proteins. After expression in E. coli the recombinant peptides were purified under denaturing conditions with the $6 \times$ His/Ni-NTA system, separated by $12 \%$ SDS-PAGE and stained with Coomassie Blue R-250 (A). Lanes 3-5 represent the clones I, I + II and I + III described in Fig. 1 (b). Immunostaining of the different recombinant peptides with the polyclonal rabbit antiserum (r-PAb) and MAbs BA10 and BG2 is shown in B-D in comparison with M. hominis FBG lysate (lane 1) and P50 (2). Positions of molecular size markers are indicated in $\mathrm{kDa}$ to the left of panel $\mathrm{A}$. 

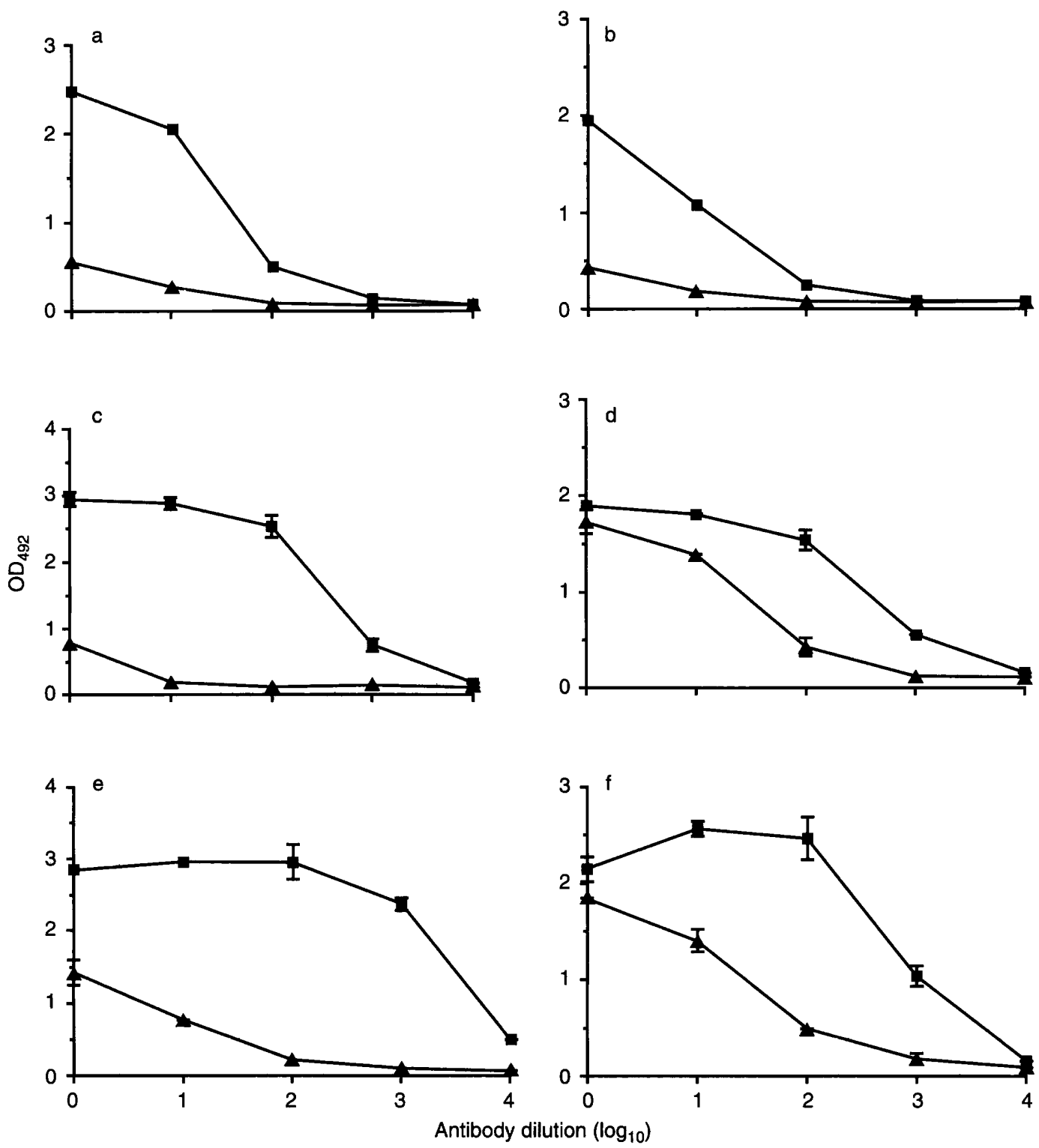

Fig. 3. Adhesion of P50 and the recombinant proteins to immobilised HeLa cells. In an adhesion assay ( $\mathbf{\square}$ ), P50 (a, c, e) and the three recombinant proteins P50-I (b), -I + II (d) and -I + III (f) representing different regions of P50 (each $400 \mathrm{ng} /$ well) were incubated for $2 \mathrm{~h}$ at $37^{\circ} \mathrm{C}$ to immobilised $\mathrm{HeLa}$ cells $\left(1 \times 10^{5}\right.$ cells/well). Cyto-adherence was detected with polyclonal rabbit antiserum $(\mathbf{a}, \mathbf{b})$ or MAbs BA10 (c, d) or BG2 (e, f). Adherence of the peptides after pre-incubation of the proteins with the appropriate antibody dilution is shown in $(\mathbf{A})$. Data represent the mean OD and SD of quadruplicate measurements.

\section{Inhibition by dextran sulphate}

DS has been shown to inhibit sulphatide-dependent adhesion to eukaryotic cells [29]. The attachment of $M$. hominis strain 1620 to WiDr cells was inhibited by $95-$ $100 \%$ with high-mol. wt DS $10 \mu \mathrm{g} / \mathrm{ml}$; low-mol. wt DS did not show such inhibition [4]. As the P50 protein had been identified as an adhesin of $M$. hominis, DS with mol.wts of 5000 and 500000 were used in a competition assay to investigate the nature of P50 binding to immobilised HeLa cells. As shown in Fig. 4, high-mol.wt DS $50 \mu \mathrm{g} / \mathrm{ml}$ was able to inhibit the binding of P50 to HeLa cells by c. 50-60\%, depending on the antibodies used for detection. Further increasing the concentration of the inhibitor had no effect.

In contrast, low-mol.wt DS up to a concentration of
$1 \mathrm{mg} / \mathrm{ml}$ had little influence on cyto-adherence. The binding of the three recombinant peptides to HeLa cells was also inhibited by high-mol.wt DS. Adherence of the recombinant peptides I, I + II and I + III was inhibited maximally at concentrations of highmol.wt DS between 50 and $100 \mu \mathrm{g} / \mathrm{ml}$. In comparison with P50, the inhibition of the recombinant peptides by high-mol.wt DS was more effective. The influence of low-mol.wt DS on peptide adherence was variable. In the case of peptide I it was only poorly effective, while the peptides I + II and I + III were increasingly inhibited at high concentrations. Sodium sulphate was tested as an inhibitor in concentrations from $10^{-4}$ to $10^{-2} \mathrm{M}$ to exclude possible ionic interaction, but showed no effect on the adherence of the peptide I+III to HeLa cells (data not shown). The competition 

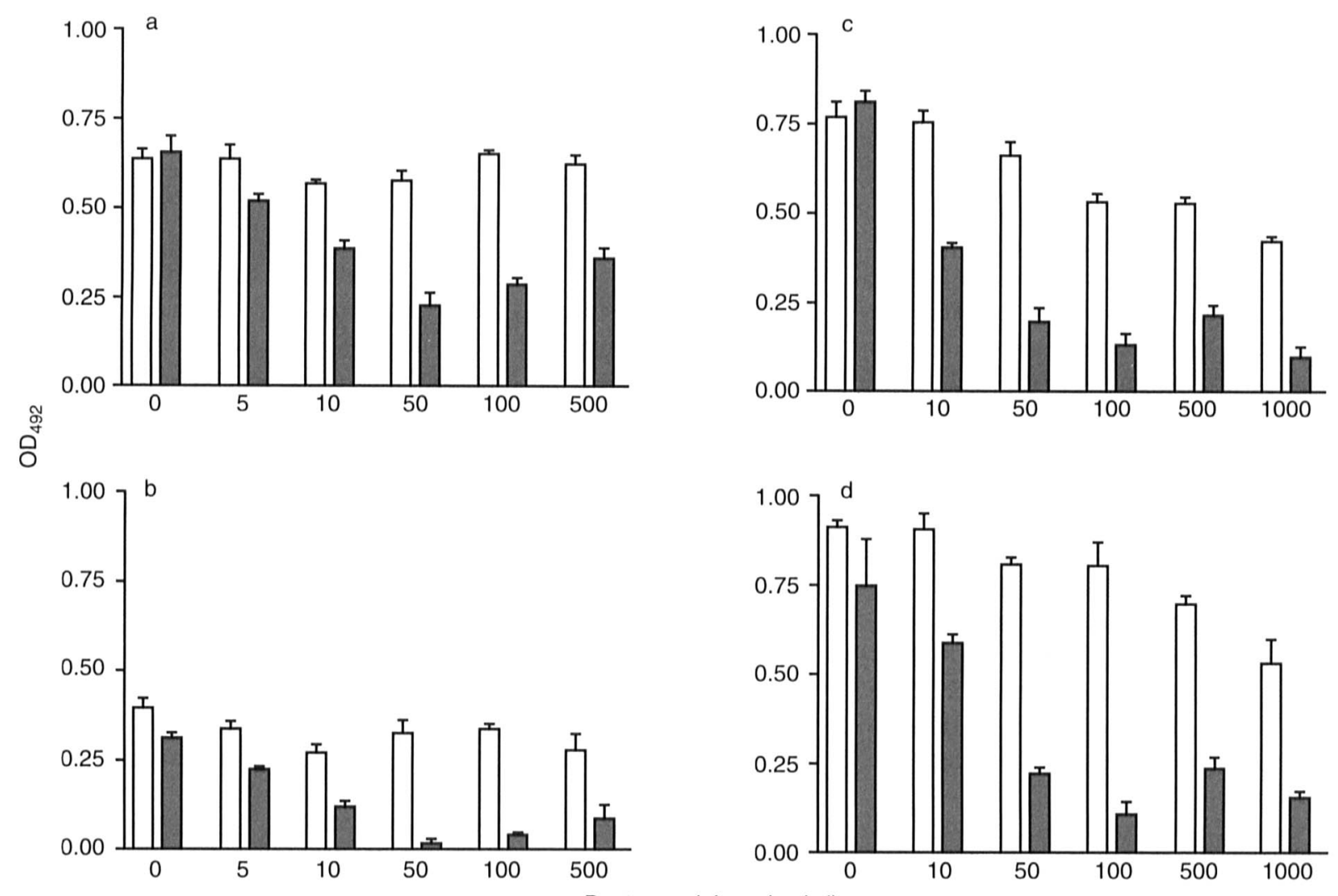

Fig. 4. Inhibition of binding of P50 (a) or the recombinant peptides P50-I (b), -I + II (c) and $-\mathrm{I}+\mathrm{III}$ (d) to HeLa cells by DS. P50 and the recombinant peptides (each $1 \mu \mathrm{g}$ protein $/ \mathrm{ml}$ ) were incubated in the presence of increasing concentrations of DS for $2 \mathrm{~h}$ at $37^{\circ} \mathrm{C}$ to immobilised HeLa cells $\left(1 \times 10^{5} /\right.$ well). Cyto-adherent proteins were detected with polyclonal rabbit antiserum as described in Materials and methods. Bars represent the mean OD and SD of quadruplicate measurements. (口), low-mol.wt DS (mol.wt 5000); (घ), high-mol.wt DS (mol.wt 500 000).

assays with DS, which were performed with both the polyclonal rabbit antiserum and MAb BG2 were similar, while MAb BA10 showed non-specific binding to HeLa cells in the presence of high-mol. wt DS (data not shown). Therefore, the assays were performed with the polyclonal serum, which was unaffected in its specificity by the presence of DS.

\section{Discussion}

The attachment characteristics of P50, an adhesin of M. hominis strain FBG, to immobilised HeLa cells were investigated by cloning and expressing different regions of the $\mathrm{p} 50$ gene in $E$. coli. Like other Mycoplasma spp., $M$. hominis utilises the codon TGA to encode tryptophan [27]. As this serves as a stop codon in $E$. coli, the internal TGA codons of the p50 gene were mutated to TGG to allow recombinant protein expression. Three cloned p50-specific PCR fragments (I, I + II and I + III) were all expressed as full length peptides in $E$. coli, but varied in their expression. The fragments code for the repeats $\mathrm{A}$, $\mathrm{A}+\mathrm{B}$ and $\mathrm{A}+\mathrm{C}$ found in the P50 molecule [15]. As expected, immunoblot analysis of the purified recombinant peptides showed that the MAbs BA10 and BG2, which were able to differentiate between the repeats $B$ and $\mathrm{C}$ of the native $\mathrm{P} 50$ protein, recognised the respective recombinant peptides, I + II and I + III.

Feldman and co-workers [14] examined the effect of MAbs directed against P50 on mycoplasma growth and viability. $M A b B G 2$, which recognised the $C$ terminal repeat $\mathrm{C}$ of $\mathrm{P} 50$, influenced the metabolism of $M$. hominis by antibody-mediated agglutination, whereas the two other MAbs (BA10 and FE6, which bind to epitopes in repeat B) had no such effect. Furthermore, analysis of the protein structure showed differences in the tertiary structure of the repeats in that repeat $\mathrm{A}$ contains a leucine zipper motif, repeat $\mathrm{B}$ a variation of this motif and, in repeat $C$, this structure is absent. Prediction of the hypothetical structure of P50 shows mainly $\alpha$-helical regions and, as previously described in immuno-electron microscopy, MAb BG2 bound to its epitope at a distance from the mycoplasma membrane [14]. This indicates that the $\mathrm{C}$ terminus of protein P50 extends away from the membrane and thus presents itself as a possible mediator of cyto-adherence.

Based on the sequence homologies of the three repeats on the one hand and considering their structural differences on the other, the present study aimed to examine whether the ability of this membrane protein 
to adhere is an attribute of a specific region (e.g., the C-terminus) or of the protein in its entirety. To investigate the adhesion capacities of distinct P50 regions recombinant peptides were produced which approximately represented the repeat regions in the combinations $\mathrm{A}, \mathrm{A}+\mathrm{B}$ and $\mathrm{A}+\mathrm{C}$. The results of adhesion-inhibition assays with the recombinant peptides indicate that, in addition to the C-terminal region, the repeats $\mathrm{A}$ and $\mathrm{B}$ are also able to adhere to HeLa cells. As described above, the affinity of peptide I (repeat A) for immobilised HeLa cells seems to be lower than that of peptides I + II and I + III. Because of the size differences, the molarity of peptide I was greater in the adherence tests and, therefore, the adherence of peptide $I$ is possibly even smaller than shown. This may be caused by the inability of the shorter peptide to form a fully functional adherent three-dimensional structure and not by the additive effect of peptide II and peptide III in the fusion proteins. As illustrated (see Results) it was not possible to express peptide II or III alone to determine their part in the binding of peptides I + II and I + III to HeLa cells.

In this study, adherence of the P50 protein was shown to be a property distributed over the entire molecule and not localised to a specific region. Recently, the P50 protein was described as being variable in size and antigenicity in $M$. hominis $[17,30]$. Whilst antigenic variability is important in evading the host defence, it is important that adherence is not adversely affected. Christiansen and co-workers performed PCR analysis on different $M$. hominis isolates and showed that various forms of the p50 gene must exist [31]. In accordance with these results, our analysis of the p50 genes from different clinical isolates showed distinct deletions of the regions encoding repeats $\mathrm{A}, \mathrm{B}$ or $\mathrm{C}$ in some cases [32].

The role of the $\mathrm{P} 50$ protein in $M$. hominis isolate 1620 , the Vaa-2 (variable-adherence-associated) antigen, was examined by Zhang and Wise with regard to the influence of this protein on cyto-adherence to cultured HeLa cells. They examined a clonal lineage (CI6.1) of $M$. hominis 1620 which exhibits a highfrequency phase variation of the $50-\mathrm{kDa}$ Vaa-2 phenotype [32]. A frameshift mutation was caused by insertion or deletion of one nucleotide in a polyAtract $166 \mathrm{nt}$ downstream of the ATG start codon which would, theoretically, result in expression of a only 4$\mathrm{kDa}$ lipoprotein. This $\mathrm{Vaa}^{-}$variant showed a $>70 \%$ reduction of cyto-adherence compared with that of the $\mathrm{Vaa}^{+}$variant, which expressed the Vaa-2 antigen. The authors related the reduced adherence of clone CI6.1 to the Vaa-2 deletion, as they found no differences in the expression of other membrane proteins and reconstituted adherence in a $\mathrm{Vaa}^{+}$variant cloned from the $\mathrm{Vaa}^{-}$variant. We have demonstrated the adherence of a recombinant peptide containing the $\mathrm{N}$-terminal region of the $\mathrm{P} 50$ protein but missing repeat $\mathrm{A}$ (data not shown). Their finding that mycoplasmal cytoadherence is markedly reduced in the event of a complete truncation of the P50 protein is in good agreement with the data presented here, indicating that P50 adherence is a property of all parts of the P50 molecule.

To further characterise the binding of P50 to host cells the present study examined the adhesion of P50 in competition with dextran sulphate. Sulphatide receptors have been shown to be one type of host cell receptor to which mycoplasmas adhere. The attachment of $M$. pneumoniae, a mycoplasma species with a tip structure, to WiDr cells has been shown to be mediated by at least two types of receptors sialylglycoproteins and sulphated glycolipids [5, 33]. Olson and Gilbert investigated the adhesion of $M$. hominis, which lacks a specific attachment organelle. They suggested that the only receptors to which $M$. hominis bind are sulphated glycolipids [4], which were found to be enriched in the endometrium. They showed by testing different saccharides and polysaccharides that, as well as fucoidan, high-mol. wt DS which was shown to inhibit sulphatide-dependent binding [29], was able to inhibit attachment of $M$. hominis isolate 1620 to WiDr cells, while low-mol. wt DS was less effective in adherence inhibition. Therefore, the present study aimed to analyse whether P50 was the mycoplasmal molecule involved in sulphatidedependent adhesion, and investigated the binding of the native P50 and the recombinant peptides to immobilised HeLa cells in the presence of dextran sulphate. The attachment of the native P50 protein as well as the recombinant peptides to HeLa cells was inhibited by high-mol. wt DS, whereas low-mol. wt DS had little effect and only at high concentrations; sodium sulphate had no effect, confirming participation of P50 in the mycoplasmal adherence [4].

In summary a leucine-zipper motif was found only in the repeats $\mathrm{A}$ and $\mathrm{B}$, whereas all recombinant peptides showed adhesion to HeLa cells. Thus the mediation of mycoplasmal adhesion to sulphatide receptors of the host would appear to be a consequence of a regular distribution of charged amino acids over the complete P50 molecule [15].

We thank Ellen Merten and Marzena Czarna for excellent technical assistance, Heiner Schaal for synthesis of the oligonucleotides and Colin MacKenzie for critically reading the manuscript.

\section{References}

1. Razin S, Barile MF. The mycoplasmas, vol IV. Mycoplasma pathogenicity. Orlando, Academic Press. 1985.

2. Kahane I, Horowitz S. Adherence of mycoplasma to cell surfaces. Subcell Biochem 1993; 20: 225-241.

3. Razin S, Jacobs E. Mycoplasma adhesion. J Gen Microbiol 1992; 138: 407-422.

4. Olson LD, Gilbert AA. Characteristics of Mycoplasma hominis adhesion. J Bacteriol 1993; 175: 3224-3227.

5. Krivan HC, Olson LD, Barile MF, Ginsburg V, Roberts DD. 
Adhesion of Mycoplasma pneumoniae to sulfated glycolipids and inhibition by dextran sulfate. J Biol Chem 1989; 264: 9283-9288.

6. Razin S. Mycoplasma adherence. In: Razin S, Barile MF (eds) The mycoplasmas, vol IV. Mycoplasma pathogenicity. Orlando, Academic Press. 1985: 161-202.

7. Gesner B, Thomas L. Sialic acid binding sites: role in hemagglutination by Mycoplasma gallisepticum. Science 1966; 151: $590-591$

8. Loomes LM, Uemura K, Childs RA et al. Erythrocyte receptors for Mycoplasma pneumoniae are sialylated oligosaccharides of Ii antigen type. Nature 1984; 307: 560-563.

9. Mardh P, Moller BR, McCormack WM. M. hominis: a human pathogen. Sex Transm Dis 1983; 10: 4.

10. Christiansen G, Mathiesen SL, Nyvold C, Birkelund S. Analysis of a Mycoplasma hominis membrane protein, P120. FEMS Microbiol Lett 1994; 121: 121-127.

11. Ladefoged SA, Birkelund S, Hauge S, Brock B, Jensen LT, Christiansen G. A 135-kilodalton surface antigen of $\mathrm{Myco}$ plasma hominis PG21 contains multiple directly repeated sequences. Infect Immun 1995; 63: 212-223.

12. Henrich B, Feldmann R-C, Hadding U. Cytoadhesins of Mycoplasma hominis. Infect Immun 1993; 61: 2945-2951.

13. Olson LD, Shane SW, Karpas AA, Cunningham TM, Probst PS, Barile MF. Monoclonal antibodies to surface antigens of a pathogenic Mycoplasma hominis strain. Infect Immun 1991; 59: 1683-1689.

14. Feldmann R-C, Henrich B, Kolb-Bachofen V, Hadding U. Decreased metabolism and viability of Mycoplasma hominis induced by monoclonal antibody-mediated agglutination. Infect Immun 1992; 60: 166-174.

15. Henrich B, Kitzerow A, Feldmann R-C, Schaal H, Hadding U. Repetitive elements of the Mycoplasma hominis adhesin p50 can be differentiated by monoclonal antibodies. Infect Immun 1996; 64: 4027-4034.

16. Hayashi $\mathrm{S}, \mathrm{Wu} \mathrm{HC}$. Lipoproteins in bacteria. $J$ Bioenerg Biomembr 1990; 22: 451-471.

17. Zhang Q, Wise KS. Molecular basis of size and antigenic variation of a Mycoplasma hominis adhesin encoded by divergent vaa genes. Infect Immun 1996; 64: 2737-2744.

18. Sambrook J, Fritsch EF, Maniatis T. Molecular cloning: a laboratory manual, 2nd edn. Cold Spring Harbor, NY, Cold Spring Harbor Laboratory Press. 1989.

19. Caruthers MH. New methods for synthesizing deoxyoligonucleotides. Genet Eng 1996; 4: 1-16.

20. Mitraki A, King J. Protein folding intermediates and inclusion body formation. Biotechnology 1989; 7: 690-696.
21. Laemmli UK. Cleavage of structural proteins during the assembly of the head of bacteriophage T4. Nature 1970; 227: $680-685$.

22. Bradford MM. A rapid and sensitive method for the quantification of microgram quantities of protein utilizing the principle of protein-dye binding. Anal Biochem 1976; 72: $248-254$.

23. Kotani H, McGarrity GJ. Rapid and simple identification of mycoplasmas by immunobinding. J Immunol Methods 1985; 85: $257-267$.

24. Blazek R, Schmitt K, Krafft U, Hadding U. Fast and simple procedure for the detection of cell culture mycoplasmas using a single monoclonal antibody. $J$ Immunol Methods 1990; 131: 203-212.

25. Ofek I, Courtney HS, Schifferli DM, Beachey EH. Enzymelinked immunosorbent assay for adherence of bacteria to animal cells. J Clin Microbiol 1986; 24: 512-516.

26. Dybvig K. Mycoplasmal genetics. Annu Rev Microbiol 1990; 44: $81-104$.

27. Yamao F, Muto A, Kawauchi Y et al. UGA is read as tryptophan in Mycoplasma capriolum. Proc Natl Acad Sci USA 1985; 82: 2306-2309.

28. Janknecht R, de Marynoff G, Lou J, Hipskind RA, Nordheim A, Stunnenberg HG. Rapid and efficient purification of native histidine-tagged protein expressed by recombinant vaccinia virus. Proc Natl Acad Sci USA 1991; 88: 8972-8976.

29. Roberts DD, Ginsburg V. Sulfated glycolipids and cell adhesion. Arch Biochem Biophys 1988; 267: 405-415.

30. Christiansen G. Genetic variation in natural populations. In Maniloff J, McElhaney RN, Finch LR and Baseman JB (eds) Mycoplasmas: molecular biology and pathogenesis. Washington, DC, American Society for Microbiology. 1992: $561-573$.

31. Christiansen G, Emmersen J, Boesen T, Jensen LT, Ladefoged $\mathrm{S}$, Birkelund S. Analysis by PCR of various forms of the Mycoplasma hominis gene encoding a variable surface exposed membrane protein, P50, associated with adhesion. IOM Lett 1996; 4: 374-375.

32. Henrich B, Lang K, Kitzerow A, Mackenzie C, Hadding U Truncation as a novel form of variation of the p50 gene in Mycoplasma hominis. Microbiology 1998; 144: 2979-2985.

33. Zhang Q, Wise KS. Localized reversible frameshift mutation in an adhesin gene confers a phase-variable adherence phenotype in mycoplasma. Mol Microbiol 1997; 25: 859-869.

34. Roberts DD, Olson LD, Barile MF, Ginsburg V, Krivan HC. Sialic acid-dependent adhesion of Mycoplasma pneumoniae to purified glycoproteins. J Biol Chem 1989; 264: 9289-9293. 